the individual and the race, it was, in a sense, forced on them. It was thus in conflict with the idea of the freedom of artistic activity-the corner-stone of current artistic theory. Mr. Miles Burkitt described the new painting of Palæolithic age found in the Pyrenean cave of Trois Frères. The painting portrays a number of animals arranged as a frieze and the figure of a masked man with stag's antlers on his head and with a tail which the author compared with the early Gallic god, always shown as masked, and the Cretan god of Minoan times. This figure elicited some interesting remarks from Miss Murray on the possible existence of a witch-cult in Palæolithic times. Mr. Leslie Armstrong exhibited a reproduction of the engraved flint found last year at Grime's Graves.

As a preliminary to the excursion made by members of the section to the excavations on Traprain Law, Mr. Alex. O. Curle gave an account of the earthworks and settlements on this site, and described the magnificent hoard of fourth-century silver plate discovered there and believed to have formed part of the booty pillaged by Saxon pirates from Gaul.
Among other communications on archæological subjects mention must be made of Miss Murray's account of her investigations in Malta, which brought to light the site of a megalithic temple at Boy en Nadur, on the Bay of Marsa Scirocco, and Dr. T. Ashby's account of the year's work in Italy and Tunisia, which has given us, particularly at Ostia and Pompeii, much fresh evidence as to Roman domestic architecture. Mr. J. Whatmough dealt with the functions of the Rehtia, the Venetic goddess of healing, suggesting that the so-called "nails" and "wedges" associated with the cult are to be explained as a specialised type of votive hair-pins with pendant axe-shaped talismans.

Mr. Stanley Casson gave a descriptive account of a journey through Macedonia undertaken under the auspices of a committee of the Association with a view to archæological investigation. Excavations of a cemetery at Chauchitsa produced a large number of objects of the Iron age, including bronze ornaments, pottery, hand- and wheel-made, some gold, and a little iron. These finds throw an interesting light upon the culture of Macedonia and its relations with Greece at this period.

\title{
Valency Bonds and the Mechanism of Organic Reactions.
}

I $\mathrm{N}$ recent years the significance of the conventional bond in the structural formulæ of organic compounds has been the subject of much speculation, more particularly in reference to the view that the bond corresponds with the field between two opposite electrical charges associated with the chemically combined atoms. The electrical conception of the valency bond has been further developed in a very interesting manner by Prof. A. Lapworth (Manchester Memoirs, vol. 64 , No. 3 , 1920) with the object of explaining the mechanism of the reactions of organic compounds.

Certain reactions, such, for example, as those of carbonyl compounds with electrolytes, suggest that the carbon atom of the carbonyl group is more electropositive than the oxygen atom of this group, in that the carbon atom invariably enters into combination with the negative ion. The relative polar character which the two atoms seem to display at the moment of chemical change may thus be indicated by ascribing + and - signs to the carbon and oxygen atoms respectively. Other reactions-for exampie, the aldol reaction-suggest that the hydrogen atom in the group $: \mathrm{CH} \cdot \mathrm{CO} \cdot$ is positive relatively to the carbon atom with which it is in combination, and it would therefore seem that the group in question can be represented by the formula

$$
\begin{aligned}
& \mathrm{H} \cdot \stackrel{\mathrm{T}}{\mathrm{C}} \cdot \stackrel{\mathrm{C}}{\mathrm{C}}: \mathrm{O} \\
& +-+
\end{aligned}
$$

in which the contiguous carbon atoms have opposite polarities. There is a good deal of evidence in favour of the existence of such latent polarisation in pairs of contiguous carbon atoms, and of the view that the carbonyl group tends to develop alternate negative and positive polarities in all the carbon atoms of any chain with which the carbonyl group is associated.

Similar effects are produced by the $\cdot \mathrm{NO}_{2}, \cdot \mathrm{SO}_{2} \cdot$, and $\cdot \mathrm{CN}$ groups, and it would seem that the divalent oxygen and tervalent nitrogen atoms are the directing or "key atoms" to which the development of the alternating latent polarisation is to be referred. The halogens are much less effective than oxygen and nitrogen, whilst hydrogen apparently exercises a perceptible influence of the opposite kind.

The extension of the influence of the "key atom" over any considerable range seems to require for its fullest display the presence of double bonds, usually NO. 2722 , VOL. IO 8$]$ in conjugated positions. The conjugated structure of aromatic compounds affords ample scope for the directing influence of the "key atom," and the behaviour of aromatic compounds is quite in accordance with the predictions of the underlying general principle to which Lapworth has given the name of the "principle of induced latent polarities." It is shown that this principle affords a very plausible explanation of many groups of well-known reactions.

The mechanism of organic reactions is also dealt with in the same volume (No. 4) by Prof. R. Robinson in a paper on "The Conjugation of Partial Valencies." The views put forward by this author have a close connection. with the above theory of the development of latent atomic polarisation by induction. It is assumed that reactive (activated) molecules are those in which a rearrangement of valencies or a change in the position of the electrons has taken place. Such rearrangement or change in position is synonymous with the development of partial valencies. To illustrate by a simple example, it is suggested that whereas the normal molecule of hydrogen chloride is represented bv the formula $\mathrm{H} \cdot \mathrm{Cl}$, the activated molecule is symbolised by $\ldots \mathrm{H} \cdots \mathrm{Cl} \cdots$, in which the dotted lines represent partial valencies of which that of hydrogen is positive and that of chlorine is negative. The author shows that the mechanism of many important reactions can be readily interpreted in terms of such activated molecules. In particular, mention may be made of the phenomena of conjugation, the representation of which is considerably simplified, whilst at the same time the conception of a conjugated system is widely extended. From the author's point of view, conjugation consists, in fact, of the transfer of a free partial valency (or latent polarity) to an adjacent carbon atom or to other carbon atoms more widely removed, and in theory there is no limit to the transmission of reactivity within the limits of the molecular aggregates.

Whether it is preferable to speak of the induction of latent polarisation or the transfer of partial valencies is not a matter of the first importance; it mav be taken for granted, however, that the views outlined by Lapworth and Robinson will be of great value in obtaining further insight into the mechanism of the reactions of organic compounds.

H. M. D. 